\title{
Effect of the degree of corrosion on bond performance of Cement Polymer Composite (CPC) Coated steel rebars
}

\author{
Deepak K. Kamde and Radhakrishna G. Pillai* \\ Department of Civil Engineering, Indian Institute of Technology Madras, Chennai, India
}

\begin{abstract}
Currently, large infrastructures (bridges, highways, etc.) are designed for more than 100 years. To achieve long service life, coated rebars (mostly, cement polymer composite (CPC) coated rebars) are being used to enhance the corrosion resistance. However, inadequately coated rebars can lead to premature corrosion. This can also affect the bond between the rebar and the concrete. To assess the effect of CPC coating on bond strength, pull-out specimens of $(150 \times 150 \times 100) \mathrm{mm}$ with $12 \mathrm{~mm}$ diameter rebar with 100 $\mathrm{mm}$ embedded length were cast and tested. For this, three replica specimens with two types of reinforcement namely, i) Uncoated steel ii) CPC coated steel were cast. To induce corrosion, additional five specimens with CPC coated steel rebars were cast with premixed chloride and cured for 28 days. During the curing period, continuous monitoring of corrosion potential and rate was done and degree of corrosion was assessed. The effect of degree of corrosion on bond of steel-concrete-coating interface was quantified. The CPC coated rebars without corrosion exhibited $10 \%$ bond reduction. CPC coated rebars with corrosion exhibited $30-70 \%$ reduction in bond strength. Also, the corrosion is found to adversely influence the stiffness of the bond.
\end{abstract}

\section{Introduction}

The service life of RC structures is defined as the duration for which structure is able to safely meet the performance requirements. Corrosion of reinforcement is one of the major causes of deterioration of reinforced concrete (RC) structures. Bond between steel and concrete significantly influences the behaviour of reinforced concrete (RC) structures. Following are three mechanisms affecting the bond between concrete and steel reinforcement: i) adhesion, ii) friction, and iii) mechanical interlock between steel and concrete [1]. Figure 2 shows the typical bond stress-slip model, where, $\tau_{\max }$ and $\tau_{\mathrm{f}}$ are maximum and residual bond stresses, respectively. Here, bond stress-slip behaviour is characterised by four parts; S1, $\mathrm{S} 2$, and $\mathrm{S} 3$ are the slips at different turning points. Region ' $\mathrm{a}$ ' (0-S1) represents the end of elastic bar response, Region ' $b$ ' (S1-S2) represents the plastification, Region 'c' (S2-S3) represents the debonding failure after plastification, and Region ' $\mathrm{d}$ ' represents the plastic bar response with bond plastification [2]. The bond stress slip behaviour is also affected by the following factors: bar diameter or surface area of rebar, cover concrete over the rebar, spacing of rebars, transverse reinforcement (stirrups), grade of concrete, surface characteristics of steel rebar (deformed/plain) and the coating applied on reinforcement [3]. This paper focuses on the coating and its influence on the corrosion and bond behaviour.

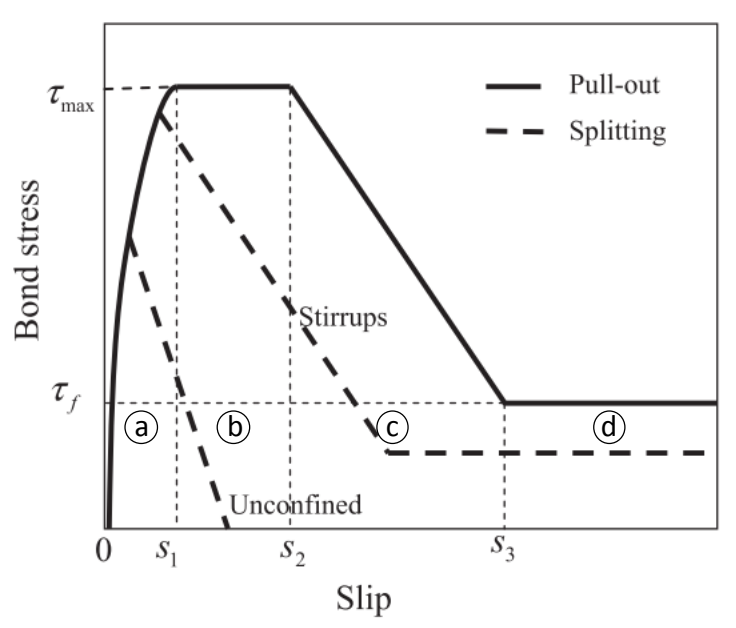

Figure 1 Typical bond stress-slip model (Jiang et al. 2018)

In the case of uncoated rebars, corrosion can result in reduction of bond between steel and concrete. A recent study showed that a mass loss less than $2.5 \%$ does not influence the bond behaviour of uncoated steel [4]. Also, it was reported that the initial corrosion products (say, up to 3\% mass loss) can result in reactionary confinement and mechanical interlocking, leading to increased frictional force between uncoated rebar and concrete [5]. When the mass loss is more than $3 \%$, the chemical adhesion between steel and concrete diminishes and only mechanical interlocking is responsible for the bond [6]. When the corrosion level is about $10 \%$, the bond strength can reduce by about 10 to $25 \%$ [7]. Figure 2 shows the

* Radhakrishna G. Pillai: pillai@iitm.ac.in 
data from literature indicating significant effect of corrosion on bond strength [8]. However, in most of the reported literature, accelerated corrosion techniques were used to induce the corrosion in the rebars. Some of such techniques could induce localized corrosion and modify the steel-concrete interface - indicating non-realistic scenario.

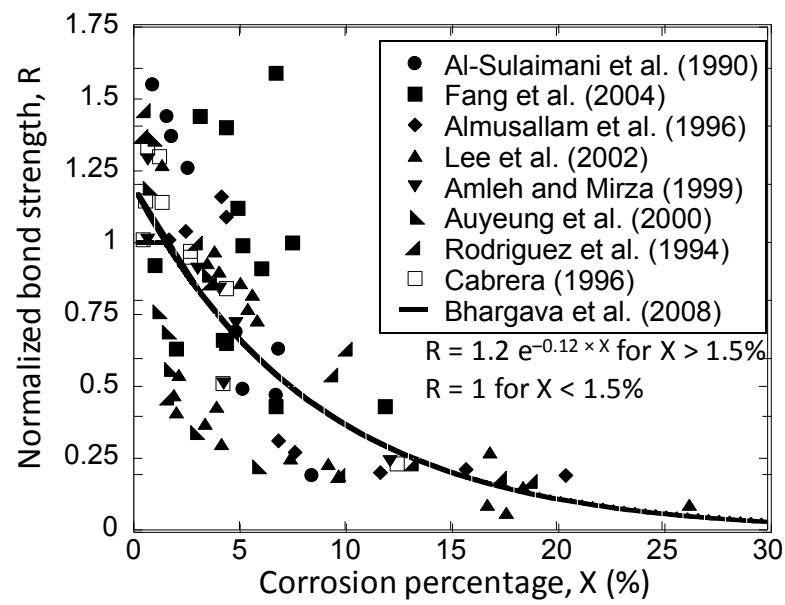

Figure 2 Normalized residual bond strength with respect to various corrosion level (adapted from Bhargava et al. 2008)

In general, the presence of cementitious coating can result in significant reduction in bond strength when compared to that of uncoated rebars. Coating can also lead to an increase in the development length by 17 to $250 \%$ than that of an uncoated steel [9]. One such coating widely used in Asian countries is Cement Polymer Composite (CPC) coating, which is a cementitious coating with thermoplastic acrylic resin as basic raw material [10]. CPC coating is also conductive in nature hence, their behaviour could be very different from that of fusion-bonded epoxy coating. Nowadays, many infrastructure systems, especially bridges, are being constructed using CPC coated steel rebars. Evidences on poor construction practices (with inadequate applications of CPC coating) are available, which could lead to premature corrosion and reduction in service life [11]. This paper presents the influence of CPC coating and corrosion on the bond strength between the rebar and concrete.

\section{Experimental Program}

To investigate the effect of coating on the bond between the rebar and concrete, pull-out specimens (as per IS 2770 - Part 1 (2007)) with following reinforcements were cast: 1) uncoated, 2) cement polymer composite (CPC) coated steel rebars. To evaluate the effect of corrosion, the specimens with CPC coated steel rebars were embedded in concrete with premixed chlorides $(2 \% \mathrm{NaCl}$ by weight of cement).

\subsection{Specimen preparation}

Steel rebars of $12 \mathrm{~mm}$ diameter were cleaned to avoid the influence of any foreign element (rust layer, oil, grease etc.) on bond between steel and concrete. Then they were coated with CPC primer coat. After a waiting period of 3 minutes, the CPC seal coat was applied (as per manufacturers guidelines). The coating thickness was maintained to a minimum of $175 \mu \mathrm{m}$ (as per IS 13620 : 2015) [12]. Pull-out specimens of $(150 \times 150 \times 100) \mathrm{mm}$ with $12 \mathrm{~mm}$ diameter rebar with $100 \mathrm{~mm}$ embedded length were cast [13]. Spiral reinforcement was placed to avoid splitting of concrete due to hoop stresses (see Figure 3 ). To study the effect of CPC coating and corrosion on bond performance, pull-out specimens were cast by embedding $12 \mathrm{~mm}$ diameter CPC coated steel rebars in chloride contaminated concrete $(2 \%$ by weight of cement). All the test specimens were moist-cured (at $25^{\circ} \mathrm{C}$ ) for 28 days.

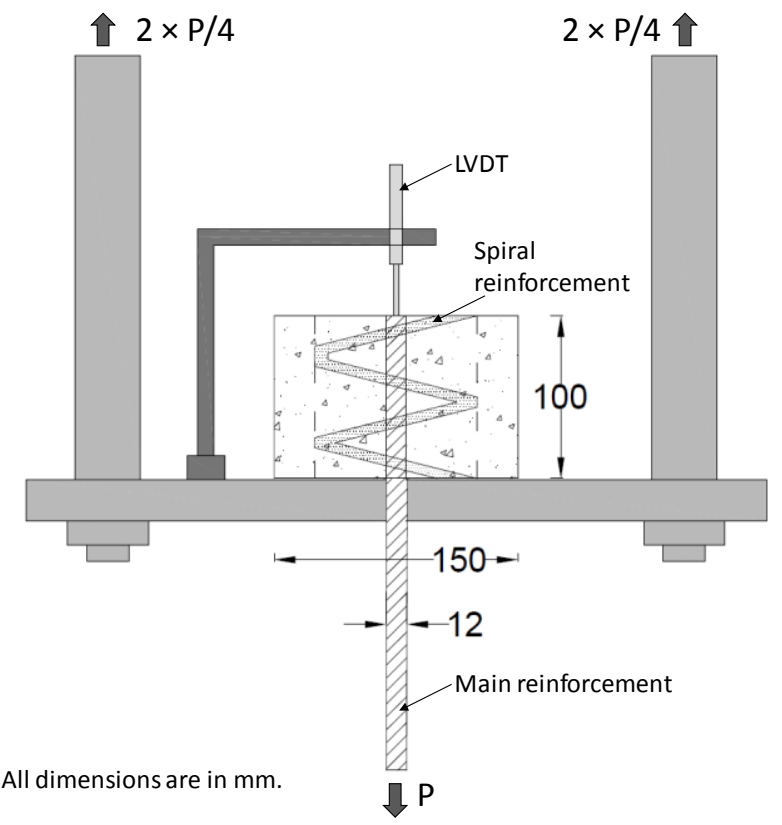

Figure 3 Schematic of pull-out test setup [as per IS-2770 (2007)]

\subsection{Exposure and pull-out test}

The test specimens were exposed to ambient room conditions of $25^{\circ} \mathrm{C}$ and $65 \% \mathrm{RH}$, until the corrosion level reached pre-defined levels. The corrosion rate was monitored at intervals of 14 days using a corrosion rate meter (GeCOR 9). Using this, the mass loss for each specimen was estimated using the Faraday's law of electrolysis (see Equation 1).

$$
m=(\mathrm{Q} / \mathrm{F}) \times(\mathrm{M} / \mathrm{z})
$$

where $\mathrm{m}$ is the steel mass loss in grams, $\mathrm{Q}$ is the total electrical charge passed in coulombs, $\mathrm{F}=96500 \mathrm{C} / \mathrm{mol}$, $\mathrm{M}$ is the molar mass of the iron, and $\mathrm{z}$ is the valency number of ions. When the specimens attained a mass loss of about 0.25 and $1.8 \%$, they were tested for their bond strength (as per IS-2770 (Part-I) 2007). 


\section{Results and discussion}

Table 1 shows the corrosion rate measurements of specimens with CPC coated steel rebars embedded in chloride-contaminated concrete. The specimens were tested for pull-out capacity (bond strength) with different degree of corrosion. Figure 4 shows the bond stress - slip behaviour of the following steel rebars embedded in concrete: (a) uncoated steel rebars, (b) Pristine CPC coated steel rebar (CPCC - P), and (c) Corroded CPC coated steel rebar $(\mathrm{CPCC}-\mathrm{C})$. Figure 4 shows the bond behaviour of pristine, uncoated rebars. Figure 4(b) and (c) shows that the post peak response of coated specimens follows a wavy pattern. This indicates the accumulation of concrete and coating at the ribs (resulting in increase in the bond stress) followed by a slip at every rib (resulting in the reduction in bond stress). Such phenomenon is not observed in the specimens with uncoated rebars. Autopsied specimens indicated shear failure in the concrete phase.

Figure 5(a) shows a dot plot of bond strengths (i.e., peak value of bond stress) in each case. The average bond strength of uncoated rebars were found to be about
14.5 $\mathrm{MPa}$. The pristine and corroded rebars with $\mathrm{CPC}$ coating exhibited average bond strengths of 12.5 and 8.7 $\mathrm{MPa}$, respectively. These are about 10 and $50 \%$ reduction, respectively, from the bond strength of uncoated rebars. Note that the bond strength of specimens with $1.8 \%$ of mass loss was found to be about $70 \%$ lower than that of specimens with uncoated rebars. Figure 5(b) shows the empirical model for peak bond stress as a function of percentage mass loss. Note that this model needs to be further modified with data from more specimens with more levels of corrosion.

Table 1 Corrosion rates of pull-out specimens with CPCC steel rebars embedded in contaminated concrete.

\begin{tabular}{|c|c|c|c|}
\hline \multirow{2}{*}{ Specimen ID } & \multicolumn{3}{|c|}{ Corrosion rate $\left(\boldsymbol{\mu A} / \mathbf{c m}^{2}\right)$} \\
\cline { 2 - 4 } & $\mathbf{1 4}$ days & $\mathbf{2 8}$ days & $\mathbf{4 2}$ days \\
\hline CPCC $-\mathrm{C} 1$ & 0 & 1.85 & - \\
\hline CPCC - C 2 & 0.02 & 1.64 & - \\
\hline CPCC - C 3 & 0.01 & 1.28 & - \\
\hline CPCC - C 4 & 0.02 & 2.03 & 8.5 \\
\hline CPCC - C5 & 0.03 & 2.19 & 8.8 \\
\hline
\end{tabular}

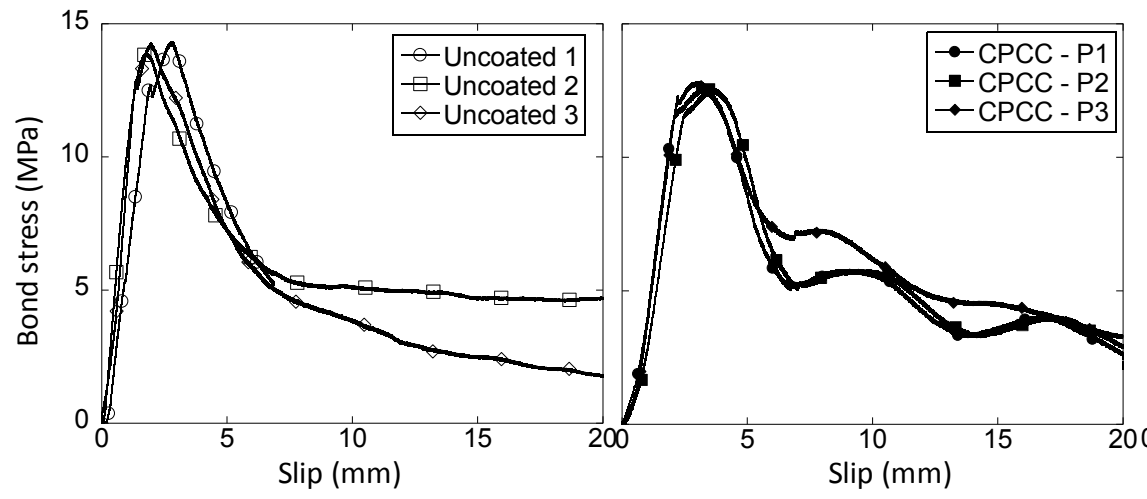

(a) Uncoated (b) CPCC - P

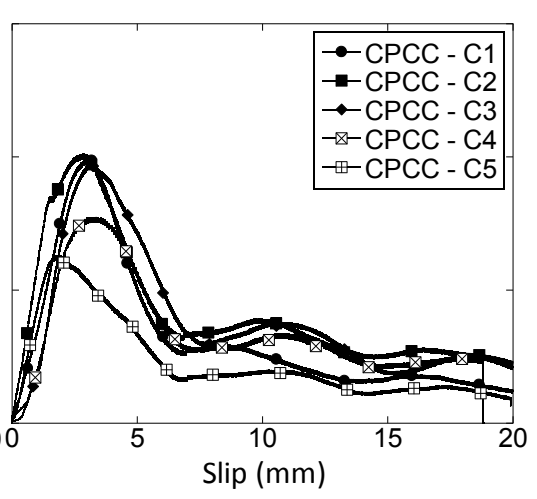

(c) CPCC -C

Figure 4 Bond stress - slip behaviour of pull-out specimens with different type of rebars.

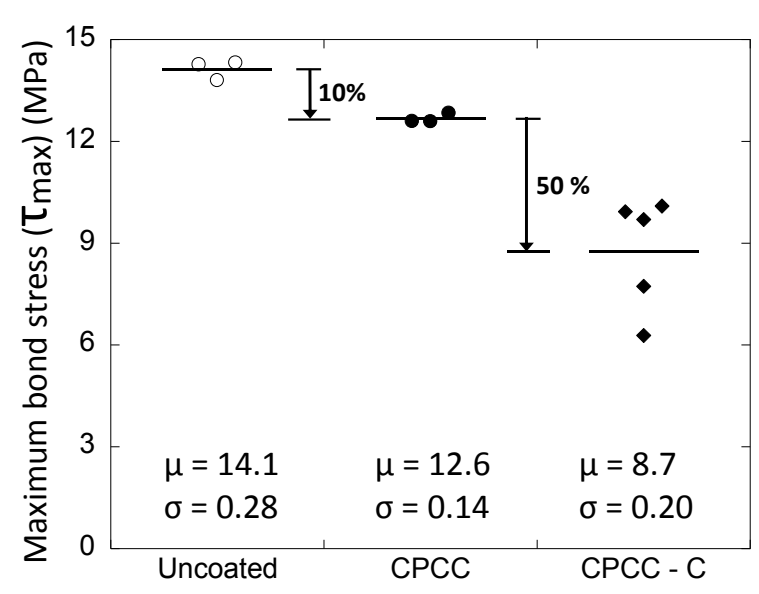

(a)

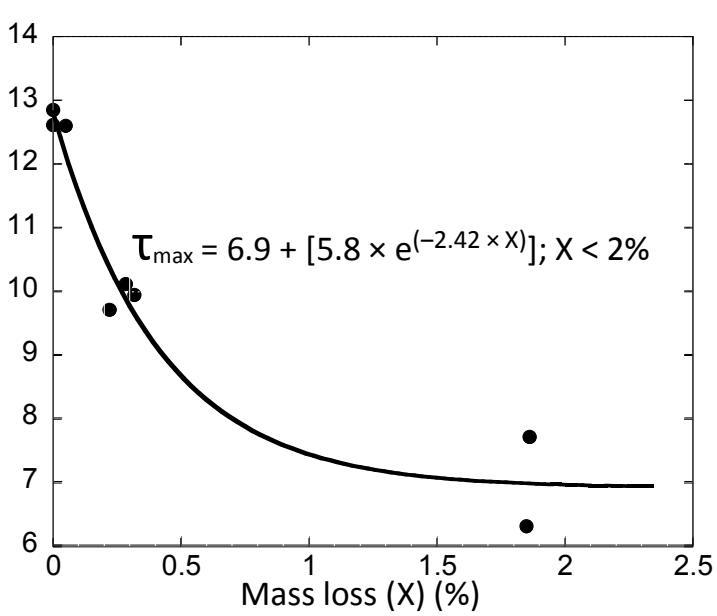

(b)

Figure 5 (a) Bond strength of uncoated, CPCC-P, and CPCC-C pull-out specimens, and (b) effect of corrosion on bond strength 
After the pull-out tests, the specimens were examined. In the case of uncoated rebars, it was found that the failure was in the bulk concrete phase - probably due to the resistance from the ribs contributing to the interlocking mechanism. Hence, the bond strength will be the result of chemical adhesion, frictional resistance, and mechanical interlock between steel and concrete.

In the case of pristine coated rebars, the bond failure depended on the adhesion and friction at the steel-coating or coating-concrete interfaces, whichever is less. Among the three specimens tested, the the slip was observed between the steel-coating interface. In addition, the accumulation of coating and cement mortar was observed at the ribs due to the mechanical interlocking. Therefore, the bond strength for pristine CPC coated rebars is governed by the chemical adhesion and friction at the steel-coating interface, and mechanical bonding at the steel-coating-concrete interface region.

In presence of corrosion between steel and coating, the chemical adhesion and friction between steel and coating will be weak. In such case, the bond strength is fully dependent on the mechanical interlocking between the rebar ribs and concrete. In the case of CPC coated rebars, even a small mass loss of about $1.8 \%$ can reduce the bond strength by $70 \%$ (Figure 5(c)). Note that in the case of uncoated rebars, 2 to $3 \%$ mass loss could actually increase the bond strength. This necessitates the need to delay the onset of corrosion. Therefore, the engineers must enforce preventive maintenance starategies to delay the onset of corrosion.

Figure 6 shows the close-up of the initial region of the bond stress - slip response of (a) uncoated steel, (b) CPC coated-pristine, and (c) CPC coated-corroded rebars.

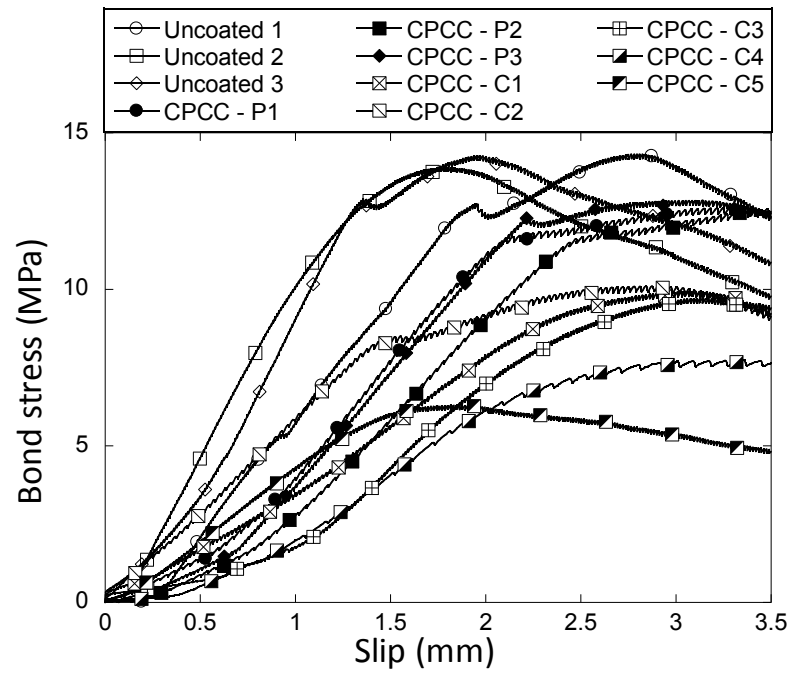

Figure 6 Close-up of bond stress-slip response of uncoated rebars, and CPC coated steel rebars before and after corrosion initiation

Bond stress - slip behaviour of pull-out specimens with CPC coated rebars with corrosion follows a sigmoid curve. Initially, with very less stress, significant slip is observed due to negligible adhesion or friction between steel and coating (due to corrosion). Subsequently, when steel ribs offer the mechanical bonding, an increase in the slope is observed. Here, the slope of the linear region of these curves represents the rate of slip of steel with respect to concrete. An average slope of $8.5,8.2$, and 4.9 was observed for specimens with uncoated, CPCC-P, and $\mathrm{CPCC}-\mathrm{C}$ type specimens, respectively (see Table 2). Higher the slope, the higher will be the stiffness of the bond. Therefore, coated specimens with corrosion exhibited significantly lower stiffness than the specimens with uncoated and coated-pristine rebars.

Table 2 Slope at linear region of stress-slip curve (bond stiffness) for uncoated and coated specimens with and without corrosion

\begin{tabular}{|c|r|r|}
\hline Specimen ID & $\begin{array}{c}\text { Slope @ linear } \\
\text { region }\end{array}$ & \multirow{2}{*}{$\begin{array}{c}\text { Average } \\
\text { slope }\end{array}$} \\
\hline Uncoated 1 & 7.32 & \multirow{2}{*}{8.5} \\
\hline Uncoated 2 & 6.76 & \\
\hline Uncoated 3 & 11.36 & \\
\hline CPCC P1 & 7.20 & \multirow{2}{*}{8.2} \\
\hline CPCC P2 & 6.46 & \\
\hline CPCC P3 & 10.83 & \multirow{2}{*}{4.9} \\
\hline CPCC C1 & 5.00 & \\
\hline CPCC C2 & 4.75 & \\
\hline CPCC C3 & 4.98 & \\
\hline CPCC C4 & 4.27 & \\
\hline CPCC C5 & 5.28 & \\
\hline
\end{tabular}

\section{Conclusions}

In uncoated steel-concrete systems, the bond stress-slip behaviour is dependent on the adhesion, friction, and mechanical interlocking between steel and concrete. In the case of coated rebars, the bond stress-slip behaviour is governed by the adhesion forces at the coating-steel or coating-concrete interfaces, whichever is less. In the case of CPC coating, the bond strength was found to reduce by about $10 \%$ even without corrosion. In the case of CPC coated rebars with corrosion, only mechanical interlocking mechanism is available for developing the bond. In such cases, even a small mass loss of about $1.8 \%$ can reduce the bond strength by as high as $70 \%$ - whereas 2 to $3 \%$ mass loss could actually increase the bond strength of uncoated rebars. This necessitates the need to delay the onset of corrosion in the concrete systems with coated rebars.

\section{References}

1. Jiang, C., Wu, Y. F., and Dai, M. J. (2018). "Degradation of steel-to-concrete bond due to corrosion." Construction and Building Materials, Elsevier Ltd, 158, 1073-1080.

2. Tastani, S. P., and Pantazopoulou, S. J. (2013). "Reinforcement and Concrete Bond: State Determination along the Development Length." Journal of Structural Engineering, 139(9), 15671581 .

3. Subramanian, N. (2005). "Development length of reinforcing bars - Need to revise Indian codal provisions." Indian Concrete Journal, 79(8), 39-46.

4. Ma, Y., Guo, Z., Wang, L., and Zhang, J. (2017). "Experimental investigation of corrosion effect on 
bond behavior between reinforcing bar and concrete." Construction and Building Materials, Elsevier Ltd, 152, 240-249.

5. A. A. Almusallam, A. S. Al-Gahtani, and A. R. Aziz, (1996). "Effect of reinforcement corrosion on bond strength." Construction and Building Materials, 10(2), 123-129.

6. Li, C.-Q., Yang, S. T., and Saafi, M. (2014). "Numerical Simulation of Behavior of Reinforced Concrete Structures considering Corrosion Effects on Bonding." Journal of Structural Engineering, 140(12), 1-10.

7. Huang, C.-H. (2014). "Effects of Rust and Scale of Reinforcing Bars on the Bond Performance of Reinforcement Concrete." Journal of Materials in Civil Engineering, 26(4), 576-581

8. Bhargava, K., Ghosh, A. K., Mori, Y., and Ramanujam, S. (2008). "Suggested Empirical Models for Corrosion-Induced Bond." Environmental Engineering, 134 (February), 221230.
9. Pei, X., Noël, M., Fam, A., and Green, M. (2015). "Development length of steel reinforcement with corrosion protection cementitious coatings." Cement and Concrete Composites, Elsevier Ltd, 60, 34-43.

10. Rajgopalan, N., Gupta, S. C., Krishna, Kant, Srira, P., Srinivasan, S., and Harit A. K., (2001). Durability of concrete structures, RDSO Report

11. Kamde, D., and Pillai R. G. (2017) Effect of surface treatment on chloride threshold of cement polymer composite coating on steel rebar, poster presentation, CORROSION conference, NACE, New Orleans, USA

12. Indian Standard 13620: (2015). "Fusion bonded epoxy coated reinforcing bars- specification." Bureau of Indian Standards.

13. IS-2770 (Part-I). (2007). "Methods of Testing Bond in Reinforced Concrete Part 1 pull-out test." Bureau of Indian Standards, New Delhi. 